\title{
LaVFisOla (laboratorium virtual fisiologi olahraga) in Faculty of Sport Science, Universitas Negeri Medan
}

\author{
Hariadi Umar ${ }^{1, *}$ \\ ${ }^{1}$ Faculty of Sport Science, Universitas Negeri Medan, Indonesia \\ *Corresponding author. Email: hariadi@unimed.ac.id
}

\begin{abstract}
The development of science and technology requires graduates of the Faculty of Sports Science to be able to apply sport science in social life. LaVFisOla is a virtual application designed to help students improve their understanding and competence in Sports Physiology courses which are the basis for implementing exercise programs, motor development, and others. This study aims to improve the competence and ability of students and also experts in sports physiology through LaVFisOla. The research method uses a mixed method, namely the modified Borg and Gall development steps and a quasi-experimental time series design (using one trial group without a control group) to see the effectiveness of using LaVFisOla. The subjects in this study were students of the Faculty of Sports Science who took the Sport Physiology course. The results of this study are the creation of a virtual exercise physiology laboratory and increasing student competence in Sports Physiology.
\end{abstract}

Keywords: Virtual laboratory, Sport science.

\section{INTRODUCTION}

The COVID-19 pandemic has had an impact on various aspects of life, including the form of mass sports

that have become individual sports. However, there are times when the limited understanding of proper exercise and excessive exercise euphoria to maintain health actually have a negative impact on one's

physical condition. Therefore, graduates of sports education are specifically required to understand a person's physical condition, one of which is through exercise physiology. This field will analyze the relationship between physiological conditions with aerobic and anaerobic activities in accordance with the principles of exercise.

As a science related to the physical condition of humans that cannot be observed directly, there are many studies of physiology or physiology that must be observed through the laboratory. Laboratories generally require a physical laboratory to conduct experiments, with complete facilities and infrastructure. This procurement certainly costs a lot, as well as the maintenance costs. The development of science and technology, then presents a hope for the presence of a virtual laboratory. The advantage of using a laboratory is to reduce the required costs, be flexible and safer [1]. In line with this, several research results reveal that the use of virtual laboratories can improve mastery of concepts, attitudes, student achievement, and higher order thinking skills (HOTS) [2][3][4][5].

The Faculty of Sports Science consists of the Department of Physical Education, Health, and Recreation, the Department of Sports Science, and Sports Coaching Education which will produce graduates in the field of sports, such as sports teachers, sports consultants, personal trainers, coaches, and others have an obligation to have competence in exercise physiology. This is because, they are the ones who will provide understanding and also as the pioneers of proper and correct exercise according to the needs and conditions of the community.

Until now, researchers have not found a physical exercise physiology laboratory in Indonesia, although there are many universities with compulsory physiology courses such as the faculties of sports science and medicine.

Moving on from the international virtual laboratory The McGill Physiology Virtual Laboratory, which contains the Exercise Physiology Laboratory, the researcher wants to develop a virtual laboratory that can be used by students of the Unimed Faculty of Sports 
Science and all students who want to explore and improve their competence in exercise physiology.

In accordance with the research map that has been planned, this research is a basic research conducted to develop a Virtual Sports Physiology Laboratory (LaVFisOla).

\section{METHOD}

This study is a quasi-experimental research with a time series experimental design that only uses one group, so it does not require a control group [6]. The results of the pre -test and post-test were then analyzed to obtain the effectiveness of the LaVFisOla FIK Unimed design. As an introduction, pretest and posttest questions are available in the LMS owned by Unimed, namely SIPDA.

The subjects in this study were students of the Faculty of Sports Science who took the Sport Physiology course. The steps in the development of the LavFisOla laboratory, namely:

\subsection{Conduct product analysis to be developed}

At this stage, a pre-test was conducted on students of the Faculty of Sports Science who took the Sport Physiology course. In this activity, the Basic Theory will be determined which will be included in th e Sports Physiology practicum. In addition, FGDs were also held within the team of lecturers who support Sports Physiology and Human Physiology.

\subsection{Develop initial product}

The initial product development process begins with identifying the theory developed and considered based on the results of the student pretest and FGD. In the initial product, a LaVFisOla guide will be generated. This guide is then used to facilitate the socialization and training process when the virtual laboratory has gone through the trial phase and is ready to be marketed.

\subsection{Expert Evaluation and Revision}

Before the LaVFisOla guide was tested at the post test stage, an evaluation was first conducted by asking for expert judgment. Evaluation is carried out regarding the appearance, content, completeness of theory and stages in the exercise physiology practicum which will be converted into a virtual laboratory.

\subsection{Evaluation}

From the results of expert evaluations and after revisions have been made, the draft LaVFi sOla guide will then be inputted into SIPDA so that students can access and study it. The next stage is a post test on the subject to see the effectiveness of using the LaVFisOla guide.

\section{ANALYZE}

Based on the results of the pretest and posttest, further analysis was carried out on the data that had been obtained. The results of the calculation of the data normality test are shown in table 1 .

Table 1 Normality One Sample Kolmogrov-Smirnov Test.

\begin{tabular}{|c|c|c|}
\hline \multirow{2}{*}{ Group } & Test & p(sig) value \\
\cline { 2 - 3 } & Pre-test & $0.762 *$ \\
\cline { 2 - 3 } & Post-test & $0.935^{*}$ \\
\hline
\end{tabular}

note: * the data is normally distributed if the p value ( $\mathrm{sig})$ $>0.05$

From Table 1, the results of the pretest and posttest were normal with $\mathrm{p}$ value $>0.05$.

To see the effectiveness of using the LaVFisOla guide, a paired T-test was calculated. The test results can be seen in Table 2 .

Table 2 Paired t-test.

\begin{tabular}{|c|c|c|c|}
\hline \multirow{5}{*}{ Group } & $\begin{array}{c}\text { Pre-Test } \\
(\text { Mean } \pm \\
\text { SD) }\end{array}$ & $\begin{array}{c}\text { Post-test } \\
(\text { Mean } \pm \\
\text { SD) }\end{array}$ & p \\
\cline { 2 - 4 } & $44.53 \pm$ & $75.47 \pm$ & 0.000 \\
& 11.8 & 10.6 & \\
\hline
\end{tabular}

Table 2 shows the results that the LaVFisOla guide is effective in increasing student competence in understanding Sports Physiology.

\section{RESULTS AND DISCUSSION}

The product produced in this study is an exercise physiology practicum guide which will then be developed into a virtual laboratory named LaVFisOla FIK Unimed. At this initial research stage, researchers and a team of lecturers of Human Physiology and Sports Physiology from 3 majors in the Faculty of Sports Science (Physical Education, Health and Recreation; Sports Science, and Sports Coaching Education) collaborated in formulating and developing guidelines for learning exercise physiology. The guide in LaVFisOla FIK Unimed contains a discussion on the analysis of the relationship between energy metabolism, nervous system, cardiovascular system, respiratory system, skeletal muscle system, and endocrine system with exercise. In addition, LaVFiOla FIK Unimed is also equipped with a simulation of the right exercise program for users based on data on their physical condition or medical history. 
Based on the results of the pretest conducted on students who took the next Sport Physiology course, the researcher and a team of lecturers conducted FGDs. FGDs were conducted to determine methods that could be applied to facilitate students' learning and understanding of the competencies that must be achieved through Sport Physiology learning. These results are then also used as a reference in determining the topic and method of describing the discussion of learning materials. From the results obtained through the FGD, the researchers then compiled a LavFisOla guide.

The LavFisOla guide that has been compiled is then submitted to experts for evaluation and consideration. Evaluation is generally related to the use of language that is easily understood by students, due to the different educational backgrounds of students.

The revised results from the experts are then submitted to SIPDA which is an LMS at FIK Unimed so that students can access it.

In the next stage, a posttest was conducted. The results of the pre test and post test were then analyzed using SPSS. From the normality test, it was found that $p$ $>0.05$, in other words, the data from the pre- test and post-test results were normal. The analysis was continued using a paired t-test to see the effectiveness of using the LaVFisOla FIK Unimed guide. From the statistical test results obtained $\mathrm{p}(\mathrm{sig})<0.05$, which means the LaVFisOla guide is effective to be used in increasing student understanding in learning exercise physiology.

\section{CONCLUSION}

The LaVFisOla Guide is effective for increasing student understanding in Sports Physiology.

\section{REFERENCES}

[1] V. Potkonjak, M. Gardner, V. Callaghan, et.al., Virtual Laboratories For Education in Science, Technology and Engineering: A Review, Computers \& Education, vol. 95, 2016, pp. 309327.

DOI:

https://doi.org/10.1016/j.compedu.2016.02.002

[2] Gunawan, A. Harjono, H. Sahidu, L. Herayanti, Virtual Laboratory Of Electricity Concept To Improve Prospective Physics Teachers Creativity, Jurnal Pendidikan Fisika Indonesia, vol. 13, 2017, pp. 102-111. DOI: https://doi.org/10.15294/jpfi.v13i2.9234

[3] A. Setiawan, A. Malik, A. Suhandi, A. Permanasari, Effect of Higher Order Thinking Laboratory on the Improvement Of Critical And Creative Thinking Skills, IOP Conference Series: Materials Science and Engineering, vol. 306, 2018, pp. 1-7. DOI: https://ui.adsabs.harvard.edu/link_gateway/2018M $\underline{\text { S\&E..306a2008S/doi:10.1088/1757- }}$ $\underline{899 X / 306 / 1 / 012008}$

[4] S. Sutarno, A. Setiawan, A. Suhandi, I. Kaniawati, D. Hamdani, Model Higher Order Thinking Virtual Laboratory: Model Praktikum Fisika Berbasis Keterampilan Berpikir Kritis Dan Pemecahan Masalah Secara Kreatif, Jurnal Pendidikan Eksakta, vol. 3, 2018, pp. 189-193.

[5] S.S. Alneyadi, Virtual Lab Implementation in Science Literacy: Emirati Science Teachers' Perspectives, Eurasia Journal of Mathematics, Science and Technology Education, vol. 15, 2019, pp. $1-10 . \quad$ DOI: https://doi.org/10.29333/ejmste/109285

[6] Sugiyono, Metode Penelitian Kuantitatif, Kualitatif, dan R\&D, Alfabeta, Bandung, 2017. 